REPRESENTACIONES DEL CUERPO

I Jornadas del Programa de

INVESTIGACIONES LITERARIAS (PRINLI)

1 - 2 DE OCTUBRE 2012 



\title{
EL CUERPO CÓSMICO COMO METÁFORA DEL ORDEN DIVINO, NATURAL Y SOCIAL: UNA INTERPRETACIÓN DEL HIMNO AL PURUȘA (R.V. X, 90)
}

\author{
Roberto Morales Harley
}

\begin{abstract}
RESUMEN
El Rg Veda es la obra literaria más antigua de la India. Consiste en una colección de 1028 himnos de carácter religioso, ordenados en 10 libros, y cuya composición se remonta aproximadamente al año 1500 a.C., con la llegada de los indoeuropeos al subcontinente. El himno al Purușa (R.V.X, 90) es un texto cosmogónico: explica el origen del mundo a partir del sacrificio de un ser humano primordial; y también cosmológico: fundamenta el orden divino, natural y social. En este trabajo, se propone una interpretación de esta imagen literaria del cuerpo como factor determinante del sistema de castas que adoptó la sociedad hindú.

Palabras clave: $\operatorname{Rg}$ Veda, Purușa, cuerpo cósmico, metáfora, sistema de castas.
\end{abstract}

\begin{abstract}
The $R g$ Veda is the oldest literary work in India. It consists of a collection of 1028 religious hymns, ordered in 10 books, whose composition dates back to approximately 1500 B.C., with the arrival of the Indo-Europeans to the subcontinent. The Purușa hymn (R.V. X, 90) is a cosmogonic text: it explains the origin of the world from the sacrifice of a primordial human being; and also a cosmological text: it supports the divine, natural and social order. In this paper, an interpretation of this literary image of the body is proposed as a determining factor for the caste systems adopted by Hindu society.
\end{abstract}

Key words: $\operatorname{Rg}$ Veda, Purușa, cosmic body, metaphor, caste system.

\section{Introducción}

El Purușa Süktam (Himno al Purușa) forma parte del Rg Veda (Veda de las estrofas), el cual, a su vez, forma parte de la Śruti (tradición revelada). En una de sus estrofas, aparece la mención literaria más antigua a la estructura jerárquica de la sociedad india. Conviene hacer la salvedad de que, durante la época Védica, existe una división social por varnas, colores,

Roberto Morales Harley. Profesor de la Escuela de Filología, Lingüística y Literatura de la Universidad de Costa Rica. Correo electrónico: roberto.moralesharley@gmail.com

Recepción: 29- 11- 2012

Aceptación: 09- 01- 2013 
término que alude a la diferencia en la pigmentación entre los indoeuropeos, de piel clara, y las poblaciones autóctonas, de piel oscura (cfr. Basham, 1989: 26-27). El término "casta" es una mala traducción del sánscrito varṇa. Ya en época del Hinduismo se establecen, de forma definitiva, las conocidas cuatro jātis, de la raíz JAN (nacer): brahmán (sacerdote), kṣatriya (guerrero), vaiśya (comerciante, agricultor) y śūdra (esclavo). Los śūdras, pueblos conquistados, son parte del sistema en el Hinduismo.

El propósito de este trabajo es ofrecer una interpretación del texto que permita valorar la elección del cuerpo como imagen representativa de esta estructura social. En primer lugar, a partir de un distanciamiento con respecto a la noción de género literario, se explica el contexto de producción del himno dentro de la literatura sánscrita. En segundo lugar, se ofrece un modelo teórico que interrelaciona los conceptos de metáfora, alegoría, imagen, al tiempo que plantea las categorías de metáfora estructural, orientacional y ontológica como puntos de referencia para el análisis del cuerpo. Finalmente, se realiza un comentario del himno, que combina los aspectos literarios con los mitológicos, las precisiones culturales con el modelo teórico, y que se centra en el cuerpo del Purușa (ser primordial) como origen y ordenador del cosmos. La idea de orden social se complementa con el divino y el natural, especialmente en las estrofas 12-14, que constituyen la parte principal del himno.

\section{La literatura sánscrita y el Rgveda (Veda de las estrofas)}

Al abordar la literatura de la India, no resultan de utilidad los mismos criterios metodológicos que se suelen emplear en literaturas de la tradición Occidental. Por ejemplo, la noción de género literario, fundamental para abordar la literatura clásica de Grecia y Roma, no se puede aplicar, sin más, a la literatura de la India. García y Huerta sostienen que "el esquema de los géneros como paradigma de las clases de textos o de las modalidades del discurso literario fue fundacional en la cultura literaria de Occidente desde La República de Platón y desde la Poética de Aristóteles" (2006: 11). Hasta allí se remonta la clasificación en épica, lírica y drama; pero estos géneros resultan insuficientes en la India.

Para el caso de India, existen también una serie de clasificaciones que determinan el análisis literario: primero, en la lengua, el sánscrito (la lengua perfectamente hecha) se opone a los prakritos (las lenguas habladas); y el sánscrito védico (de los Vedas), al sánscrito clásico (de la épica); segundo, en la mitología, se habla de dioses y mitos védicos, por un lado, y de dioses y mitos hindúes, por otro; y, tercero, en la literatura, conviene tener presente la distinción entre Śruti y Smrti.

La literatura se clasifica de la siguiente manera: Śruti proviene de la raíz ŚRU (escuchar) y constituye la tradición revelada, Smrti proviene de la raíz SMR (recordar) y constituye la tradición memorizada. Para la Śruti, los rsșis (videntes) tuvieron acceso a los textos por la vía visual, y los transmiten por la auditiva: vieron los textos que se manifestaban por intervención de la divinidad, y los repiten para que sean oídos por las siguientes generaciones. Malamoud llama la atención sobre el sistema metafórico implícito en esta visión de mundo: "nótese la sucesión de metáforas: los rssis vieron los Vedas, pero los han legado a las generaciones posteriores bajo la forma de un texto que ha de ser escuchado y repetido" (Pannikar y Pòrtulas 2000: 68).

Se trata de una literatura oral, religiosa y orientada al ritual. Los textos principales son los Vedas, voz derivada de la raíz VID (ver). Se le conoce como traȳ vidyā (triple ciencia), puesto que incluye tres grandes colecciones: Rgveda (Veda de las estrofas), Sämaveda (Veda de las melodías) y Yajurveda (Veda de las fórmulas rituales). Posteriormente, se añade una cuarta 
colección: Atharvaveda (Veda de los Atharvas, nombre de la tribu que tuvo la revelación). Estas colecciones de textos se componen entre el 1500 a.C. y el 500 a.C.

Cada colección está conformada por varios estratos: (a) las Samihitās (recopilaciones de himnos y plegarias), (b) las Brāhmaṇas (tratados en prosa acerca de brahman, el saber sagrado), (c) los Āranyakas (libros del bosque con interpretaciones simbólicas o esotéricas), (d) las Upanișads (tratados en prosa sobre las implicaciones especulativas de índole filosófica), y (e) el Vedānga (apéndices o elementos finales de los Vedas).

Los Vedas son la primera manifestación literaria de la India. La cultura de los invasores indoeuropeos, quienes poseían una visión patriarcal y traían su propia literatura religiosa, acabó por fusionarse con la de las poblaciones autóctonas, donde las divinidades femeninas ocupaban un rol preponderante. El pueblo védico era guerrero, preocupado por las conquistas y posesiones, pero también por las relaciones amorosas. Estos temas se encuentran presentes en los Vedas. También sobresalen en estos himnos algunos dioses, que posteriormente serán suplantados en sus funciones por otros (Indra por Viṣṇu, Rudra por Siva), o pasarán a la categoría de deus otiosus. Muchas veces se les caracteriza con una terminología similar o hasta con las mismas frases hechas. Este rasgo recibe el nombre de henoteísmo.

Con respecto a las características formales, los Vedas están compuestos en un sánscrito védico, forma más antigua del idioma sánscrito, diferente por su riqueza léxica, su compleja morfología y sus particularidades sintácticas, especialmente en la subordinación. Como rasgos de estilo de estos himnos se puede mencionar "la libertad en el orden de las palabras, las elipsis, los paréntesis, las construcciones forzadas, y además, las hipérboles, el lenguaje muchas veces enigmático, las veladas referencias, las imágenes formadas por elementos heterogéneos" (Tola, 1968: 16).

El Rgveda es el más antiguo y merece ser estudiado, en opinión de Tola (1968: 18), por varias razones: (1) "es el monumento lingüístico indoeuropeo más antiguo y completo que se posee", (2) "es, además, el punto de origen y el fundamento de todas las doctrinas de la India clásica", (3) "constituye la principal fuente de información para el conocimiento del Vedismo".

La colección de himnos incluidos en el Rgveda ofrece temas variados: dioses soberanos (Mitra, Varuṇa), dioses guerreros (Indra), divinidades femeninas (Pṛthivī, Ușas, Vāc), divinidades colectivas (Rudras, Maruts), animales (aves, caballos, ranas), actividades cotidianas (bebida, juego, armas, discusiones), actividades rituales (soma, muerte, invocación), por mencionar algunos. Parte de esta temática es el mito cosmogónico, representado, en mayor medida, en el décimo maṇdala, libro, por el Himno de la creación (X, 129) y por el Himno al Purușa (X, 90). En el primer caso, lo Uno se ofrece como respuesta parcial a la pregunta por el origen, pero luego es puesta en duda (tal vez ni el creador sabe el origen de su creación). En el segundo, la imagen elegida es el cuerpo cósmico (el creador es la creación).

Renou (1956: 247-248) señala que esta suerte de opus operans et operatum se encuentra también en otras fuentes de la literatura de la India: ya sea como sacrificio simbólico (BṛadĀranyaka-Upaniṣad I, 1 y VI, 2; Chāndogya-Upanișad III, 16-17; Taittirīya-Upanișad, I, 7; Muṇdaka-Upanișad, II, 1), ya como gigante cósmico (Kaușītaki-Upanișad, III, 2; ŚvetāśvataraUpaniṣad, III, 8; Chāndogya-Upanișad III, 16).

\section{Metáforas y alegorías en las imágenes literarias}

Según la concepción tradicional, la metáfora es una especie de comparación: al existir dos elementos que tengan algún aspecto en común, uno de ellos queda caracterizado en 
términos del otro. Ejemplo: cabellos de oro. Los cabellos y el oro pueden compartir el color amarillento, por lo que se deduce que se trata de cabellos rubios.

[La metáfora] Figura importantísima (principalmente a partir del barroco) que afecta al nivel léxicosemántico de la lengua y que tradicionalmente solía ser descrita como un tropo de dicción o de palabra (a pesar de que siempre involucra a más de una de ellas) que se presenta como una comparación abreviada y elíptica (sin el verbo). (Beristáin 1988: 308)

Por su parte, la alegoría es una suerte de metáfora continuada: dados dos elementos complejos, se establecen entre ellos una serie de paralelismos a partir de un grupo de metáforas. Ejemplo: el camino de la vida. La vida se asemeja al camino en varios puntos: el nacimiento es el inicio del camino y la muerte su final; las etapas de la vida son tramos; las decisiones, encrucijadas; los conocidos, caminantes... Cada una de las comparaciones es una metáfora, mientras que la totalidad del sistema metafórico constituye la alegoría.

La alegoría o metáfora continuada (llamada así porque a menudo está hecha de metáforas y comparaciones) se ha descrito como una figura que en un nivel inferior de lengua, se compone de metasemas, mientras en un nivel superior constituye un metalogismo... Se trata de un "conjunto de elementos figurativos usados con valor traslaticio y que guarda paralelismo con un sistema de conceptos o realidades", lo que permite que haya un sentido aparente o literal que se borra y deja lugar a otro sentido más profundo, que es el único que funciona y que es el alegórico. Esto produce una ambigüedad en el enunciado, porque éste ofrece simultáneamente dos interpretaciones coherentes, pero el receptor reconoce sólo una de ellas como la vigente. (Beristáin 1988: 35)

Por último, resulta pertinente detenerse en el concepto de imagen literaria. Esta sería una creación poética de carácter alegórico o metafórico, es decir, la forma literaria de un sistema complejo, que cuenta con un doble sentido, el literal y el figurado. Ejemplo: el cuerpo cósmico en el himno al Purușa. El microcosmos es una representación a escala del macrocosmos, por lo que el cuerpo humano se corresponde con el cuerpo cósmico en cada una de sus partes.

\footnotetext{
Lo que se llama imagen literaria es la introducción de un segundo sentido, ya no literal sino analógico, simbólico, "metafórico", en un trozo de texto: el resultado es la sustitución de un término -llamado tema o comparado- por otro -llamado foro o imaginado- que no presenta con el primero más que una relación de analogía que descubre la intuición o la sensibilidad del autor y del lector. (Marchese y Forradellas 1994: 206)
}

Esta imagen del cuerpo cósmico se aproxima a la noción de alegoría. Por una parte, el Rgveda está lleno de metáforas, hecho que ha sido puesto en evidencia por Renou (1965: 10): "el aparato metafórico está muy desarrollado, y constituye lo que se ha llamado el 'galimatías' del Veda". Y, por otra, tales metáforas no son fortuitas: se unen para formar imágenes literarias, especialmente con respecto al plano cósmico. Agud (2004: 11) habla de mitos "de contenido psicológico", como aquellos que esbozan algún tipo de "alegoría cósmica":

\footnotetext{
Si bien en la mitología india clásica predominan los temas cósmicos: los mitos de creación, los mitos sobre dioses que realizaron hazañas heroicas de carácter cosmogónico, muchos relatos revelan una dimensión muy diferente y que entrona con una tradición muy antigua. Curiosamente en fases aún considerablemente arcaicas existe en la India un tipo de mito que, sin dejar de presentarse como cosmogónico, es ante todo de contenido psicológico. Explica el cosmos mediante una alegoría de la personalidad, o también a la inversa, la personalidad mediante una alegoría cósmica. (Agud 2004: 11)
}

Es muy acertada esta valoración, en tanto considera la interrelación de las cadenas metafóricas. Ahora bien, en un sentido menos tradicional, la metáfora puede ubicarse más cerca de esta idea de alegoría y, en consecuencia, de la de imagen literaria. Se trata de las llamadas "metáforas de la vida cotidiana", planteadas por Lakoff y Johnson (2004). 
Estos autores proponen una serie de metáforas que pasan a formar parte del lenguaje como frases usadas con poca o ninguna consciencia de su origen metafórico, o del sistema metafórico de pensamiento en el cual surgieron. Se clasifican en tres grupos: las estructurales, en las que "un concepto está estructurado metafóricamente en términos de otro" (Lakoff y Johnson 2004: 50); las orientacionales, donde el procedimiento "no estructura un concepto en términos de otro, sino que organiza un sistema global de conceptos con relación a otro" (Lakoff y Johnson 2004: 50); y las ontológicas, definidas más adelante.

Para el himno al Purușa, son relevantes las metáforas orientacionales y las ontológicas. Las metáforas orientacionales permiten la organización del sistema de pensamiento a partir de la experiencia espacial. Sobre la base de la oposición fundamental entre "arriba" y "abajo", se puede establecer toda una serie de contraposiciones (Lakoff y Johnson 2004: 50 y ss): "feliz es arriba; triste es abajo", "lo consciente es arriba; lo inconsciente es abajo", "salud y vida son arriba; enfermedad y muerte son abajo", etc. Esta forma de razonamiento se aplica también a la estructura social:

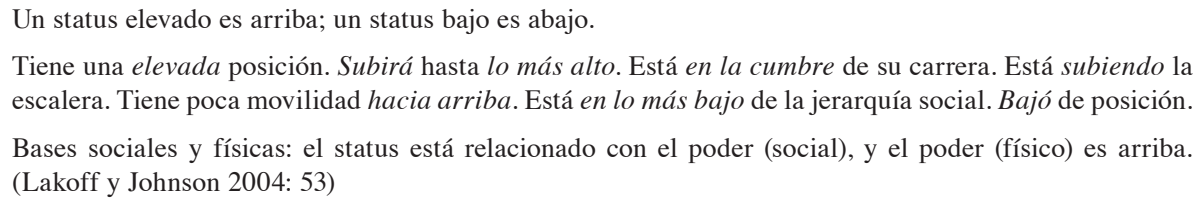

De este modo, la metáfora orientacional permite precisar el alcance de la imagen del cuerpo cósmico: aceptado que el cuerpo cósmico es como el cuerpo humano, y que ambos tienen cabeza, tronco, brazos y piernas, se puede establecer una jerarquía. De este modo, las partes ubicadas más arriba corresponden a las que poseen un mayor poder social. La orientación básica manejada concibe la región de "arriba" en términos más favorables que las de "abajo". Estas nociones eran conocidas para los indoeuropeos de época védica tardía, y quizás desde un período anterior.

\footnotetext{
La sociedad védica tardía distingue claramente entre "arriba" y "abajo"; en los textos aparece una diferenciación entre "rico y pobre", entre "el que alimenta y el que es alimentado", entre "el que come y el que es devorado", y ponen de manifiesto de manera realista la desigualdad del mundo en parejas de conceptos opuestos. (Embree y Wilhelm 2004: 26)
}

Por otra parte, las metáforas ontológicas permiten la organización del sistema de pensamiento a partir de la experiencia con objetos. Así, si "la inflación es una entidad", se puede afirmar (Lakoff y Johnson 2004: 64 y ss): "la inflación está bajando nuestro nivel de vida", "si hay mucha más inflación no sobreviviremos", hay que combatir la inflación", etc. Las metáforas ontológicas incluyen a las alegorías y se forman gracias a la percepción del cuerpo.

\footnotetext{
De la misma manera que las experiencias básicas de orientación espacial humana dan lugar a metáforas orientacionales, nuestras experiencias con objetos físicos (especialmente nuestros propios cuerpos) proporcionan la base para una variedad extraordinariamente amplia de metáforas ontológicas, es decir, formas de considerar acontecimientos, actividades, emociones, ideas, etc., como entidades y sustancias. (Lakoff y Johnson 2004: 64, las itálicas son agregadas)
}

Entonces, la imagen literaria del cuerpo se puede entender a partir de la combinación de la metáfora orientacional "un status elevado es arriba; un status bajo es abajo" y de la metáfora ontológica "el cosmos es un cuerpo". La primera daría cuenta de la ordenación en castas; la segunda, de la correspondencia entre el macrocosmos y el microcosmos. 


\section{4. $\quad$ El Puruṣa sūktam (Himno al Puruṣa)}

A continuación, se ofrecen las dieciséis estrofas del himno, según la traducción de Tola (1968: 265-270), seguidas de un comentario.

1

Innumerables cabezas

tenía el purusha, innumerables ojos, innumerables pies.

Por todas partes

cubría a la tierra

y aun en diez dedos la sobrepasaba.

El Purușa es el ser humano primordial. En sánscrito (Macdonell 1965: 165), puruṣa ( $p \bar{u} r u s ̣ a$, alargado para efectos de la métrica) significa: hombre, ser humano (en plural, gente o humanidad), persona; encargado, funcionario; principio personal y anímico, alma, principio personal supremo, alma universal, Espíritu Supremo; hombre primordial de quien el universo evolucionó (similar a nārāyaṇa); miembro de una raza o generación; persona gramatical.

Sobre el Purușa, Agud (2000: 33-34) aporta algunas referencias dignas de mención. En primer lugar, la idea de un sacrificio original, presente en himnos védicos dedicados a personajes como Prajāpati o Viśvakarman, es decir, demiurgos (e.g., X, 81). En segundo lugar, las versiones del mito en las Upaniṣads, donde la creación es una autolimitación del ser trascendente (e.g., Bṛhad-Āraṇyaka-Upanișad I, 4; Muṇḍaka-Upanișad II). Y, por último, la evolución del concepto mismo hasta un principio del ser (e.g., en la escuela Sāmkhya, purușa es el 'espíritu' que se opone a la prakrti, la 'materia').

En el himno, el ser humano se encuentra en el origen mismo de la creación. La nada no puede surgir de la nada, pues esto sería una contradicción lógica: el universo surge de algo, la existencia surge del ser que la prexistía. En el origen, era el Purușa, y el Purușa era la totalidad. Dos características sobresalen de primera entrada. Por un lado, el Purușa posee un cuerpo, con cabeza y pies, esto es, con principio y fin; y con ojos, es decir, con una vía de contacto entre el adentro y el afuera. El potencial para el establecimiento de límites y para su observación precede a su propia existencia.

Por otro lado, este ser es onmiabarcante: todos sus atributos físicos los posee en cantidades innumerables, imposibles de determinar por medio del conocimiento humano; por tanto, cubre a la tierra por completo, y aún la sobrepasa. El Puruṣa es más grande que el mundo, porque en sí contiene al mundo. Después de él, la tierra es lo primero mencionado. La tierra es el sustento de la creación, pero el Purușa es la causa del sustento, es lo que posibilita la fundamentación.

\section{2}

El purusha es todo esto,

lo que ha sido,

lo que será.

Es el señor de lo inmortal

y de lo que crece con el alimento. 
La infinitud del Puruṣa se extiende del ámbito espacial al temporal. Mediante una predicación, se le define en términos de totalidad, y, posteriormente, esta afirmación presente se proyecta hacia el pasado y hacia el futuro. El Purușa es, fue y será. Incluso in illo tempore hay que pensar a este ser primordial en retrospectiva. La idea es característica de una noción cíclica del tiempo: esta creación es una de las creaciones, que no solo espera su reabsorción, sino también una nueva creación. El universo, en las coordenadas espacio-temporales, se expande y se contrae, comienza y termina; el Purușa origina estas coordenadas, sobrepasa el espacio y el tiempo, está antes y después, lejos y cerca de la existencia.

Por estas razones, es preciso reconocer el señorío del Puruṣa. El señor es aquel que se encuentra por encima de los demás. Hay aquí un primer ejemplo de la metáfora orientacional, la cual distingue entre arriba y abajo. ¿De qué es señor el Purușa? De todo: lo inmortal y lo mortal. Con la muerte como punto de referencia, toda la realidad se puede clasificar en términos de mortal o inmortal. Así, al regir este ser primordial por sobre ambos, nada escapa a su reinado. Aquello que crece con alimento es, también, lo que decae, lo variable, lo material, lo humano, lo mortal.

3

Tal es su grandeza,

pero más aun es el purusha.

De él

una cuarta parte

son todos los seres;

las tres restantes

lo inmortal, que está en el cielo.

Se ha afirmado que el Puruṣa es la totalidad; se añade, ahora, que es todo y más. Llama particularmente la atención el proceso elegido para continuar la descripción: la única forma de amplificar los dominios de un ser que por sí mismo incluye a la totalidad de la existencia es, no hacia afuera, sino hacia adentro. ¿Qué partes componen el todo? ¿Cómo está conformado el ser primordial?

Básicamente, el Puruṣa está dividido en cuatro partes. El cuatro es un número fundamental dentro del sistema de pensamiento indio: cuatro son los puntos cardinales, las patas de la vaca, las etapas del mundo, las etapas de la vida; cuatro serán también las castas. El cuatro es el número de la perfección. A modo de ejemplo, el primero de los períodos en el Hinduismo, en el cual la vaca que sostiene al mundo se apoya en sus cuatro patas, es la Krrta Yuga (Edad Perfecta). Kṛta, de la raíz KR (hacer), es lo hecho, lo acabado, lo perfecto.

El Purușa es perfecto. Tiene cuatro partes, que en el cuerpo corresponderían a los dos brazos y las dos piernas, con que este ser abarca toda la creación. En esta estrofa, las cuatro partes se dividen en dos grupos en una proporción de 3 a 1. La parte menor comprende a todos los seres, en un plano inferior; la mayor, lo divino, en un plano superior. Desde el punto de vista humano, la tierra está abajo y el cielo arriba. Una vez más, opera la metáfora orientacional: abajo está lo malo, los hombres, lo mortal; arriba, lo bueno, los dioses, lo inmortal. La inmortalidad es el bien más deseado por los seres humanos, mortales por naturaleza, y, en consecuencia, se ubica en la sección espacialmente mejor valorada. 
Con tres cuartas partes

se trasladó hacia arriba;

la cuarta se manifestó aquí,

y luego se extendió por todos lados,

hacia lo que come,

hacia lo que no come.

Naturalmente, lo semejante tiende a lo semejante. Lo alto tiende a lo alto: lo divino del Purușa, sus tres cuartas partes de inmortalidad se desplazan hacia arriba. Por el contrario, lo bajo tiende a lo bajo: lo humano del Purușa, su cuarta parte de mortalidad se manifiesta aquí.

Dos ideas resultan dignas de mención. En primer lugar, la noción de desplazamiento hacia arriba presupone un punto de partida localizado abajo. Tres partes se mueven y una permanece. El Purușa, como ser, parte de entre los seres a los que también origina. Es, a un tiempo, causa y consecuencia, puesto que escapa a las coordenadas lógicas. En segundo lugar, el deíctico indica un punto de enunciación que permite deducir el movimiento inverso: los poetas que componen el himno lo reciben en la región inferior, proveniente de las alturas.

La cosmogonía se funde con la cosmología. El Puruṣa se reparte y luego se expande. El orden interno es la base del externo: como el Puruṣa consta de partes, así es también el mundo. Y empieza a manifestarse una jerarquía a base de oposiciones: lo inmortal y lo mortal y, después, lo animado y lo no animado. A estas dos categorías corresponderían las perífrasis de lo que come y lo que no come.

5

Del purusha nació Virat,

de Virat nació el purusha.

No bien nació,

sobrepasó a la tierra,

por abajo y por arriba.

De las oposiciones se pasa a las contradicciones. Puruṣa y Virāj, de la raíz VR (cubrir), son dos seres: el primero es el principio masculino; la segunda, el femenino, la parte activa, luminosa y dominante, como una especie de energía o Śakti primitiva (cfr. Renou 1956: 248). Cada uno nació del otro. Desde la percepción humana, lo aceptable es que los padres engendren a los hijos. Afirmar lo contrario es ya una contradicción, dado que una cosa no puede originar a otra prexistente. Sin embargo, el planteamiento va más allá: no solo se afirma la negación, sino que afirmación y negación coexisten. Así, los hijos pueden engendrar a los padres, a la vez que estos engendran a los hijos.

Se trata de una aporía, en la medida en que se intente su abordaje desde el pensamiento lógico. En el ámbito mítico, se cuenta con ciertas libertades. El Puruṣa es causa y consecuencia de la creación, en la medida en que el rito actualiza el mito. Sin Puruṣa no hay creación y sin creación no hay Purușa. No significa esto que uno sea el resultado del otro, o, más bien, quiere decir que ambos los son: la reciprocidad indica complementariedad. Como el mundo surge de un sacrificio, existe el sacrificio en el mundo, lo que permite que haya un sacrificio originario. Se trata de un ciclo cuyo inicio no se remonta a un acontecimiento específico, sino al ciclo mismo. 
Una vez creado el mundo, el creador pudo nacer en él. Sobrepasó a la creación desde su nacimiento, por arriba y por abajo. No podía ser de otro modo: debía ser más grande para poder contenerla.

\section{6}

Al ofrecer los dioses el sacrificio con el purusha como ofrenda, la primavera fue la grasa, el verano la leña, el otoño la oblación.

Esta es la primera mención expresa del sacrificio. El Purușa es una ofrenda, un sacrificio en el sentido etimológico. Es una forma de unir lo humano con lo divino, de tornar sagrado lo profano, de acercar el plano inferior al superior. Es el sacrificio último: gracias a él hay mundo y hay orden en el mundo. El sacrificio, como rito, repite el mito de creación. Cada vez que se ofrece un sacrificio, el mundo se crea; y cada vez que el mundo se crea, se ofrece un sacrificio.

Asimismo, inician en esta estrofa una serie de comparaciones cuyo propósito es evidenciar la correspondencia entre el microcosmos y el macrocosmos. El Purușa es un cuerpo, del cual surge el cuerpo del mundo. El primer elemento de comparación son las estaciones. El ser primordial beneficia a los seres: con las estaciones, las cuales son partes del cuerpo cósmico, y con los productos del sacrificio, componentes del cuerpo ritual.

La primavera es la grasa; el verano, la leña; el otoño, la oblación. Grasa, leña y oblación son fundamentales en el ritual: sin grasa y sin oblación, el fuego deja de arder; sin leña, el fuego ni siquiera se puede encender. El centro del ritual védico es el fuego, por eso Agni es el dios principal de los brahmanes. El fuego es un elemento ambivalente: produce luz, calor, vida; aunque también destrucción, devastación y muerte. Debe ser propiciado y el mejor medio para lograrlo es el ritual. La ofrenda de productos, sumada a la recitación de fórmulas específicas, se convierte en el fundamento de un sacrificio orientado a obtener el favor de los dioses.

\section{7}

Como sacrificio,

sobre la paja ritual

consagraron al purusha,

que nació en el principio.

Con él sacrificaron

los dioses, los Sadhyas y los rishis.

El Purușa es el sacrificio, es el ser consagrado. El que prexiste al principio nace en el principio, para hacer posible el principio mismo. Los primeros beneficiados por esta acción ritual son los que se encuentran más arriba en la jerarquía: los dioses, únicos inmortales; los sadhyas, especie de intermediarios para el sacrificio; y los rșis, seres premiados con la revelación.

No se puede obviar la localización favorable de los rsșis, autores del texto en cuestión. Ahora bien, no es asunto de proselitismo, sino de firme creencia en su estado superior, y, en alguna medida, de legitimación. 
8

En este sacrificio,

ofrecido totalmente,

se recogió la grasa coagulada.

Con ella crearon a los animales,

que viven en el aire,

en los bosques y en las aldeas.

El sacrificio fue total, porque el Purușa es totalidad. De los restos, surgen los seres: la grasa origina a los animales. Hay una nueva clasificación: domésticos y salvajes. A esto corresponderían las perífrasis de los que viven en los bosques y en las aldeas. Lo más relevante es que este primer grupo de criaturas se ubica también en las regiones elevadas. Al ser animales capaces de volar, pueden remontarse a los cielos y casi rozar la esfera divina.

9

De este sacrificio,

ofrecido totalmente,

nacieron las estrofas

y las melodías;

de él nacieron los versos

y las formas litúrgicas.

La estrofa repite el inicio de la anterior y agrega información nueva. De este modo, se entiende que los nuevos resultados de la creación dependen tanto de los anteriores como de los originales. Se comienza a formar una cadena de creación. Tras las aves, seres naturales superiores, aparecen algunas creaciones artísticas igualmente elevadas. La poesía y la música, ámbitos de pertenencia, respectivamente, de estrofas y versos, y de melodías y formas litúrgicas, son esferas sagradas, en tanto dependen de seres de una categoría superior.

Existe un interesante mito, en el cual se explica que de la Palabra (Suparṇī, "la bien alada") nacen las formas métricas, las cuales, al ser las más elevadas manifestaciones del lenguaje poético, son representadas como pájaros. Participan en la traída de Soma (bebida ritual): jagatī, triștubh y gāyatrī son todas estrofas de cuatro sílabas. La jagatī pierde tres y queda de una; la triștubh pierde una y queda de tres; la gāyatrī recoge las cuatro que perdieron sus hermanas y se convierte en una estrofa de ocho sílabas. Entonces, las nuevas formas métricas ayudan en el sacrificio: la gāyatrī en la mañana (con sus ocho sílabas); la triștubh al mediodía (con once sílabas: las ocho de su hermana y las tres propias); y la jagatī en la tarde (con doce sílabas: las once de sus hermanas y la única suya).

La estrofa denominada gāyatrī es la más importante para el sacrificio: "Meditemos en el adorable esplendor de Savitar. ¡Ojalá estimule nuestros pensamientos!" (R.V. III, 62, 10; cfr. Tola, 1968: 49).

10

De él nacieron los caballos, y las bestias que tienen dentada la boca; y nacieron las vacas, las cabras y los corderos. 
Luego vienen los animales que habitan la tierra. Caballos y vacas ocupan el primer lugar. Los caballos son animales muy apreciados por las poblaciones nómadas indoeuropeas. Su preponderancia, en labores que van desde el simple transporte hasta los enfrentamientos bélicos, se evidencia en algunos himnos védicos (IV, 38; IV, 39), dedicados a Dadhrika, corcel del rey Trasadasyu, del cual se dice que vale más incluso que su jinete. Por su parte, consabida es la relevancia de la vaca en la cultura india. De ella provienen los productos del sacrificio: leche y ghee (mantequilla clarificada). Siempre respetando el nuevo orden, el ganado mayor viene seguido del menor: cabras y corderos.

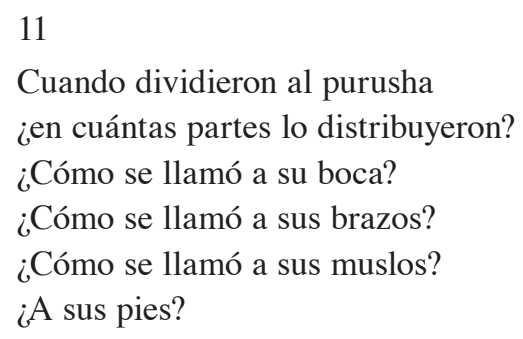

La estrofa 11 constituye un preámbulo a la parte central del himno. Platea una serie de interrogantes cuyo objetivo es llegar a un mayor nivel, sino de comprensión, sí al menos de participación en la experiencia de la creación. Una pregunta inicial sobre la repartición cósmica abre la puerta a otras tres que, en alguna medida, ya anticipan las respuestas. La distribución del cosmos es como la de un cuerpo: sus partes son boca, brazos, muslos, pies.

Las estrofas 12, 13 y 14 desarrollan esta idea, respectivamente, en los planos social, divino y natural. La imagen del cuerpo sirve como metáfora del orden: propiamente en esta sección revela el himno su carácter cosmológico. Se incluye algunos cuadros, cuyo propósito es aclarar los planteamientos.

\section{2}

Su boca fue el brahmán, sus dos brazos el guerrero, sus muslos el vaishya; de sus pies nació el shudra.

Cuadro 1. Jerarquía social

\begin{tabular}{|l|l|l|}
\hline Estrofa 12 & Imagen del cuerpo & Orden social \\
\hline \multirow{2}{*}{ Región superior } & Boca & Brahmán \\
\cline { 2 - 3 } & Brazos & Kșatriya \\
\hline \multirow{2}{*}{ Región inferior } & Muslos & Vaiśya \\
\cline { 2 - 3 } & Pies & S̄ūdra \\
\hline
\end{tabular}

La estrofa 12 establece, mediante la metáfora del cuerpo, una jerarquía social. Quizás por una interpolación (cfr. Tola y Dragonetti 2003: 219), constituye la mención literaria más antigua al sistema de castas de la India. Estas se afianzarán en la cultura en época posterior, con el Hinduismo. La concepción es la siguiente: un ser humano tiene un papel propio dentro de la sociedad, el cual le es asignado por nacimiento, jāti, de la raíz JAN (nacer). Su deber, 
dharma, de la raíz DHṚ (sostener), consiste en aceptar su condición, la cual depende del grupo social en el que ha nacido.

En el Hinduismo, hay una clara distinción en cuatro castas: brahmán (sacerdote), kșatriya (guerrero), vaiśya (comerciante, agricultor) y śüdra (esclavo). Los brahmanes se ocupan del sacrificio, la recitación de los textos sagrados, las relaciones con las divinidades; los kșatriyas, de la guerra, la administración del gobierno, las relaciones entre los seres humanos; los vaiśyas originalmente se dedicaban a los cultivos, pero con los cambios históricos devinieron también los encargados de la actividad mercantil; a los śüdras les corresponden las labores más despreciables, las cuales no podrían efectuar los miembros de otras castas.

El sistema presenta algunas oposiciones importantes: la primera, brahmanes, kșatriyas y vaiśyas frente a śúdras, puesto que los primeros son dvijāti, nacidos dos veces, son más puros y se ocupan de labores propias de su clase, mientras que los otros son más impuros y sirven a las otras castas. La segunda, brahmanes y kșatriyas frente a vaiśyas y súudras, dado que aquellos dominan y estos son dominados; y la tercera, constantemente brahmanes y kșatriyas se enfrentan por el poder.

La estrofa manifiesta, por un lado, una estructuración en la cual la función social se corresponde con la localización espacial de las partes correspondientes del cuerpo: el orden descendente de brahmán, kșatriya, vaiśya, śüdra, coincide con el de boca, brazos, muslos, pies. Se trata, pues, de la metáfora orientacional. Por otro lado, cada parte del cuerpo elegida posee una función similar a la del grupo social: con la boca se habla, como hablan los brahmanes al recitar los Vedas; con los brazos se lucha, como luchan los kșatriyas al conquistar otros pueblos; con las piernas se camina, como caminan los vaiśyas para producir o comerciar; y el cuerpo se sostiene con los pies, los siervos que atienden a las otras partes para que pueden desempeñar a cabalidad sus roles. En el planteamiento se aprecia, igualmente, la metáfora ontológica.

Por último, así como brahmanes y kșatriyas se oponen a vaiśyas y śüdras, del mismo modo, la boca y los brazos se ubican, con el ombligo como punto medio, en el extremo opuesto del cuerpo con respecto a las piernas y los pies.

13

De su mente nació la luna,

del ojo nació el sol,

Indra y Agni de su boca;

de su aliento nació Vayu.

Cuadro 2. Orden divino

\begin{tabular}{|l|l|l|l|}
\hline Estrofa 13 & Imagen de la cabeza & Orden Divino & Estrofa 13 \\
\hline Inmaterial & Mente & Luna (Soma) & Fenómeno \\
\hline Material & Ojo & Sol (Sūrya) & Fenómeno \\
\hline Material & Boca & Indra y Agni & Divinidad \\
\hline Inmaterial & Aliento & Vāyu & Divinidad \\
\hline
\end{tabular}

Por medio de una sinécdoque, en la estrofa 13, la cabeza, la parte superior y principal, se concibe como la totalidad del cuerpo. La imagen de la cabeza es la más adecuada para establecer en el orden en el plano de arriba: el divino.

Así como en el Hinduismo existe una Tríada Hindú, la trimurti, constituida por Brahma (el creador), Viṣnu (el preservador) y Śiva (el destructor); del mismo modo, en el Vedismo se 
cuenta con una tríada Védica, conformada por Agni, Indra y Sūrya (cfr. Wilkins 1998: 16). En el himno, estas tres divinidades ocupan la parte central. El Sol, que completa la vuelta del mundo de los vivos al mundo de los muertos, es el único que todo lo ve, el representante de la omnisciencia divina. En un himno védico (X, 37, 1), se le llama "ojo de Mitra y Varuna".

Si el Sol es el ojo, Agni e Indra son la boca. Agni, el fuego, representa el sacrificio. Un dios con una mitología rica en imágenes, aparece acompañado de sus madres (i.e. la leña, vid. X, 1) y sus hermanas (i.e. las llamas, vid. X, 5). Es el dios principal de los brahmanes. Por su parte, Indra, el guerrero, representa las hazañas militares: mató a la serpiente Vṛtra (la sequedad) y liberó las aguas de los Siete Ríos (Vitasta, Asikni, Parushni, Vipat, Shutudri, Sarasvati y Sindhu; vid. I, 32), sobrepasó a los dioses y subyugó a los bárbaros (II, 12), y concedió las riquezas al ario (IV, 26). Su atributo es el rayo, con el que hiere. Es, pues, el dios de los kṣatriyas.

Llama la atención, con respecto a la estrofa anterior, la ubicación en un mismo plano de Indra y Agni. Esto sería un reflejo de las mencionadas oposiciones que se establecen entre las castas. La imagen se completaría con el Sol. Cabe destacar el hecho de que, a raíz de la superioridad de estos tres dioses, gran parte del panteón védico se suele catalogar en tres grupos (cfr. Wilkins 1998: 23 y ss): (a) dioses del fuego (Agni), (b) dioses de la luz (Sūrya, junto con Puṣan, Mitra-Varuṇa, los Aśvins y Ușas), y (c) dioses de la tormenta (Indra, junto con Indran̄i, Parjanya, Vāyu y los Maruts).

Ahora bien, a estos dos elementos de naturaleza material, el ojo y la boca, corresponden, respectivamente, dos de naturaleza inmaterial: la mente y el aliento. La mente representa la cognición, la modalidad más elevada de visión. Está equiparada a Soma, palabra sánscrita que posee varios sentidos: por una parte, es la planta soma, de la cual se extrae el jugo soma, con el que se elabora la bebida ritual soma; por otra, es el dios Soma, que se manifiesta en los elementos cambiantes, como la planta en el mundo humano, y la luna en el divino. El soma, producido por destilación, es la bebida preferida de los dioses védicos (e.g. Indra es un gran bebedor de soma, vid. I, 32). A su vez, el aliento representa el soplo vital, la modalidad más elevada de respiración. Se asimila a Vāyu, dios del viento.

Al igual que en la estrofa anterior, hay una correlación entre las partes de la cabeza y las funciones divinas, en la cual se puede ponderar el valor de la metáfora ontológica. Se observa, asimismo, una jerarquía, si bien ordenada no en forma escalonada (desde arriba hacia abajo), sino mediante un énfasis (desde el centro hacia los extremos). El énfasis se puede apreciar en dos recursos: la cabeza que representa al cuerpo y la tríada divina que hace otro tanto con el panteón.

Empero, existe también una diferencia con respecto a la estrofa precedente: es posible establecer dos tipos de asociaciones entre las partes. En la columna de la izquierda, del lado del sentido literal, los elementos se oponen así: el primero (mente) y el último (aliento) frente al segundo (ojo) y el tercero (boca), es decir, lo inmaterial y lo material. En la columna de la derecha, del lado del sentido figurado, se oponen de este modo: el primero (Luna) y el segundo (Sol) frente al tercero (Indra y Agni) y el último (Vāyu), esto es, el fenómeno y la divinidad.

14

De su ombligo surgió el espacio;

de su cabeza se desarrolló el cielo;

de sus pies nació la tierra,

y de sus orejas las regiones.

Así construyeron a los mundos. 
Cuadro 3. Orden natural

\begin{tabular}{|l|l|l|}
\hline Estrofa 14 & Imagen del cuerpo & Orden natural \\
\hline Centro & Ombligo & Espacio \\
\hline Arriba & Cabeza & Cielo \\
\hline Abajo & Pies & Tierra \\
\hline Extremos & Orejas & Regiones \\
\hline
\end{tabular}

De la estrofa 12 a la 13, se pasó del cuerpo a la cabeza; de la 13 a la 14, se vuelva de la cabeza al cuerpo. Establecido el orden social, se procedió a su contraparte divina, para luego regresar al ámbito natural.

Esta estrofa combina las dos jerarquías empleadas anteriormente: arriba sobre abajo, centro sobre extremos. Las partes del cuerpo elegidas para esta comparación constituyen límites: la cabeza hacia arriba, los pies hacia abajo, el ombligo en el centro y las orejas a los lados. Hay un elemento repetido, los pies, lo cual se explica por la necesidad ineludible del sustento: no hay castas $\sin s \bar{u} d r a s$, ni vida sin tierra, ni cuerpo sin pies. Los pies corresponden a la tierra.

La contraparte de la tierra es el cielo. El cielo, como los dioses que lo habitan, corresponde a la cabeza. La contraposición está presente, de otras formas, en varios mitos cosmogónicos (cfr. Guevara 1976: 29-38): (a) el hombre y la mujer como partes de la semilla cósmica (Brhadāranyaka Upanișad I, 4, 1-5), (b) el cielo y la tierra como partes del huevo cósmico (Chāndogya Upanișad III, 19, 1-4), (c) el ser y el no ser en el himno de la creación (Rg Veda X, 129), (d) los mundos de agua, rayos de luz, muerte y aguas que emanan del àtman (Aitareya Upanișad I, 11, 1-25).

Cabeza y pies ejemplifican la metáfora orientacional; ombligo y orejas, la ontológica. En la mitología, el ombligo es un símbolo del centro, un axis mundi. Como parte central del cuerpo físico, coincide, en la imagen literaria, con la parte central del cuerpo cósmico. Al haber ombligo, hay interconexión de los planos cósmicos, los cuales ya han quedado fijados, de acuerdo con la ordenación previa. Mientras que en las primeras estrofas el Puruṣa prexistía a las coordenadas espacio-temporales, ya en esta fase hay un espacio.

El espacio se proyecta hacia las regiones. ¿Por qué elegir los oídos para esta imagen? Basta recordar la secuencia metafórica que fundamenta la literatura védica: la revelación fue vista, y se repite para ser escuchada. El Veda se recita para ser escuchado en todas las regiones, como en un mito que explica el origen de las cuatro cabezas de Brahma: Sarasvatī, su esposa, surgió de su cuerpo, como Șatarūpā (la de cien formas). Brahma, movido por la belleza de la muchacha, la siguió con su vista. Ella se movió hacia la derecha del dios, luego hacia atrás y hacia la izquierda. Como resultado, le brotó una nueva cabeza en cada dirección. Así, con cada boca, Brahma recita un Veda, y el texto sagrado resuena en todas las regiones.

15

Siete fueron los cercos,

$\mathrm{y}$ tres veces siete

los haces,

que se hicieron con la leña,

cuando los dioses,

al realizar el sacrificio,

ataron como víctima al purusha. 
El número siete es importante en el pensamiento indio: si alguien camina alrededor de sus padres siete veces, es mejor que si fuera alrededor del mundo; si una pareja se casa, los esposos deben dar siete pasos juntos para consolidar su unión; y si dos personas dan siete pasos juntos por el mismo camino, se vuelven amigos. Estos números se asocian con Agni (cfr. Wilkins 1998: 24): representado con tres piernas, siete brazos y siete rayos que emanan de su cuerpo.

Los cercos y los haces determinan los límites en este sacrificio originario del Puruṣa. En el sacrificio védico participan siete sacerdotes, presididos por un hotr (sacrificador).

16

Los dioses ofrecieron

el sacrificio

al sacrificio.

Se establecieron

por primera vez

las normas.

Al firmamento llegaron sus poderes,

donde residen

los antiguos Sadhyas y los dioses.

La estrofa 16 es la última del himno. La repetición de términos evidencia la correspondencia entre microcosmos y macrocosmos, entre cuerpo físico y cuerpo cósmico: los dioses ofrecen el sacrificio al sacrificio. El Puruṣa deviene causa y consecuencia, parte activa y pasiva, agente e instrumento.

Se establecieron por primera vez las normas: hay una estrecha relación entre mito y rito, entre cosmogonía y cosmología. Esta frase sintetiza la idea de orden (divino, natural y social). Con las normas se fija un código de conducta. El mundo natural y el social son tales gracias a su participación en el plano divino. El planteamiento se cierra con una mención del firmamento como sitio del poder. Una vez más, opera la metáfora orientacional.

\section{Conclusiones}

Con esta interpretación del himno al Purușa (R.V. X, 90), se ha valorado la imagen literaria del cuerpo para representar la estructura social que, con el Hinduismo, dará lugar al sistema de castas. Para ello, se ha contextualizado la literatura sánscrita, no a partir de la clasificación occidental de los géneros literarios, sino desde la oposición entre Śruti (tradición revelada) y Smrti (tradición memorizada). En la revelación de los Vedas, se ha enfatizado el carácter metafórico y alegórico; este aspecto se ha enriquecido con el aporte conceptual de las "metáforas de la vida cotidiana", especialmente la metáfora orientacional "un status elevado es arriba; un status bajo es abajo" y la metáfora ontológica "el cosmos es un cuerpo".

La metáfora orientacional se puede apreciar en aspectos como la idea de señorío (estrofa 2), la oposición entre el espacio de los hombres y el de los dioses (estrofa 3), la estructura jerárquica del sistema de castas (estrofa 12), la oposición entre la cabeza y los pies (estrofa 14), o la noción del firmamento como sitio del poder (estrofa 16). La metáfora ontológica se encuentra presente en relaciones como las que hay entre las funciones de las castas y de las partes de cuerpo (estrofa 12) o de los dioses y de las partes de la cabeza (estrofa 13). También, en la elección de puntos de referencia como el ombligo y las orejas (estrofa 14), frente a otros de índole orientacional como la cabeza y los pies. 
La creación védica desde el ser humano primordial ha evidenciado una estrecha relación entre cosmogonía y cosmología, mito y rito, macrocosmos y microcosmos, esfera divina y esfera humana. La explicación incluye el ámbito espacial y el temporal, la amplificación hacia afuera-adentro y hacia arriba-abajo, la ordenación en niveles jerárquicos, el empleo de números específicos (el cuatro y el siete, e incluso lo innumerable), el uso de oposiciones y contradicciones, y, lo más importante, los componentes del sacrificio.

La parte central del himno está constituida por las estrofas 12-14. Respectivamente, la imagen del cuerpo justifica el orden social (la boca es el brahmán; los brazos, el kșatriya; los muslos, el vaiśya; los pies, el śüdra); la imagen de la cabeza, el orden divino (la mente es Soma; el ojo, Sūrya; la boca, Indra y Agni; el aliento, Vāyu); y también la imagen del cuerpo, el orden natural (el ombligo es el espacio; la cabeza, el cielo; los pies, la tierra; las orejas, las regiones). El cuerpo humano identificado con el cosmos simboliza, por un lado, la unión, de lo sagrado con lo profano (los dioses intervienen en el ámbito humano), y, por otro, la repartición, característica del ritual védico (los humanos influyen en el ámbito divino). Unión y repartición son manifestaciones de la interconexión de los planos. Mediante la palabra sagrada del himno védico, pronunciada en sánscrito, se logra una integración de las castas, la cual, sin embargo, excluye a los "otros", quienes no pertenecen al sistema.

\section{Bibliografía}

Agud, Ana. 2004. "El mito en la India". Sileno: variaciones sobre arte y pensamiento. 17: 7-16.

Agud, Ana y Francisco Rubio. 2000. La ciencia del brahman. Once Upanișad antiguas. Madrid: Totta.

Basham, Arthur. 1989. The Origins and Development of Classical Hinduism. New York: Oxford University Press.

Beristáin, Helena. 1988. Diccionario de retórica y poética. México, D. F.: Porrúa.

Embree, Ainslie y Friedrich Wilhelm. 2004. India. Historia del subcontinente desde las culturas del Indo hasta el comienzo del dominio inglés. México, D. F.: Siglo XXI.

García, Antonio y Javier Huerta. 2006. Los géneros literarios: sistema e historia (Una introducción). Madrid: Cátedra.

Guevara, Gitanjali de. 1976. Juego Cósmico. Caracas: Monte Ávila.

Lakoff, George y Mark Johnson. 2001. Metáforas de la vida cotidiana. Madrid: Cátedra.

Macdonell, Arthur. 1965. A Practical Sanskrit Dictionary. Oxford: Oxford University Press.

Marchese, Angelo y Joaquín Forradellas. 1994. Diccionario de retórica, crítica y terminología literaria. Barcelona: Ariel.

Panikkar, Raimon y Jaume Pòrtulas (Eds.). 2000. Volumen V. Las mitologías de Asia. Barcelona: Destino.

Renou, Louis. 1956. Hymnes spéculatifs de Véda. Paris: Gallimard. 1965. Las literaturas de la India. Buenos Aires: EUDEBA.

Tola, Fernando. 1968. Himnos del Rig Veda. Buenos Aires: Sudamericana.

Tola, Fernando y Carmen Dragonetti. 2003. "El Vedismo. Los Vedas. Lo uno como origen de todo. El orden cósmico". Asociación Española de Orientalistas. 39: 217-241.

Wilkins, W. 1998. Mitología hindú. Védica y puránica. Barcelona: Edicomunicación. 